\title{
Japanese Speaking Personnel Proficiency Deficiencies: A Case Study of Japanese Education in Thailand
}

\author{
Nareenoot Damrongchai \\ Graduate School of Language and Communication, National Institute of Development Administration, Bangkok, \\ Thailand
}

\begin{abstract}
During the past 10 years, Japanese language learning has become popular in Thailand, which can be seen in the rise of private Japanese language teaching institutes as well as the number of Japanese related programs provided in many universities around the country. However, in spite of the incremental increase in number of learners, most Japanese entrepreneurs consider it to be critically difficult to find qualified Japanese speaking personnel in Thailand. The main purpose of this article is to explore the reasons for this problem and find a proper solution by studying the expectations of Japan studies stakeholders towards the qualification of Thai graduates in Japan Studies as well as Japanese Studies curriculum. A questionnaire has been distributed to two different groups: those who graduated in a field related to Japan studies, and Japanese employers who live in Thailand, followed by interviews with key informants. The findings show that there is a gap between the expectation of the students and the entrepreneurs towards the qualification of Thai graduates in Japanese Studies, in other words, among the Thai and the Japanese. Most Thai students consider the proficiency in Japanese language to be the most important ability required, while Japanese entrepreneurs consider those who have the abilities of comprehension, good perspective and use of Japanese in business as most important. Moreover, the research found that both students and entrepreneurs want the curriculum to be more practical and applicable to careers.
\end{abstract}

Index Terms - Thailand, Japan studies, curriculum development, education, human resources

\section{INTRODUCTION}

\section{A. Japanese in Thailand}

Japan and Thailand have maintained a long affable relationship that can be traced back to the 15th century when relations between Ryukyu, present day Okinawa, and Thailand's historical capital of Ayudhaya have been recorded. Trade between the two countries became active during the 17th century, at which time the Japanese community in Ayudhaya flourished. But after Japan adopted the policy of closing their country to the outside world in 1639, the community began to decline (Kakazu, 2010). Centuries later, the relations bewteen Japan and Thailand modern history restarted with the Declaration of Amity and Commerce between Japan and Thailand in 1887. At that time, Japanese experts in various fields were dispatched to Thailand to contribute to the modernization of the country. Symbolized by the close relationship between the Imperial Family of Japan and the Royal Family of Thailand, the two countries now engage in many forms of personnel exchange, carried out in various fields, such as politics and economics, among others. In 2007, Japan and Thailand celebrated the 120th Anniversary of the establishment of diplomatic relations with many memorial cultural events (Ministry of Foreign Affairs, 2011).

Statistics from the Immigration Bureau of Thailand reveals that although the number of Japanese tourists has tended to decline since the coup in 2006, the total amount of Japanese tourists traveling to Thailand each year was never less than 1 million people in the passing 10 years (Immigration Bureau, 2010).

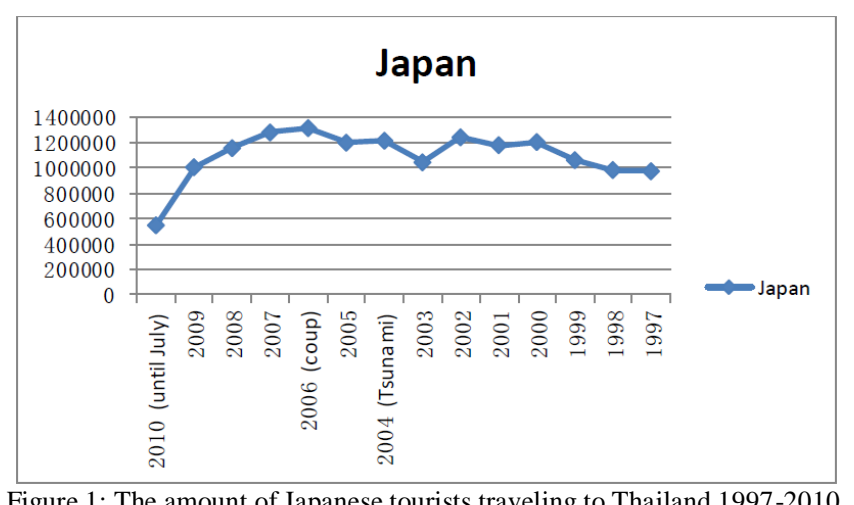

Figure 1: The amount of Japanese tourists traveling to Thailand 1997-2010. 
Regarding Japanese residents in Thailand, it has been reported that in 2001 the amount of Japanese who live in the country was 22,731 people and, 10 years later in 2010, the number was 47,251, or double (Embassy of Japan in Thailand, 2010). The report also shows that highest number of Japanese residents in Thailand work at Japanese enterprises and their family. More details about reasons for living in Thailand can are shown in table 1.

TABLE 1:

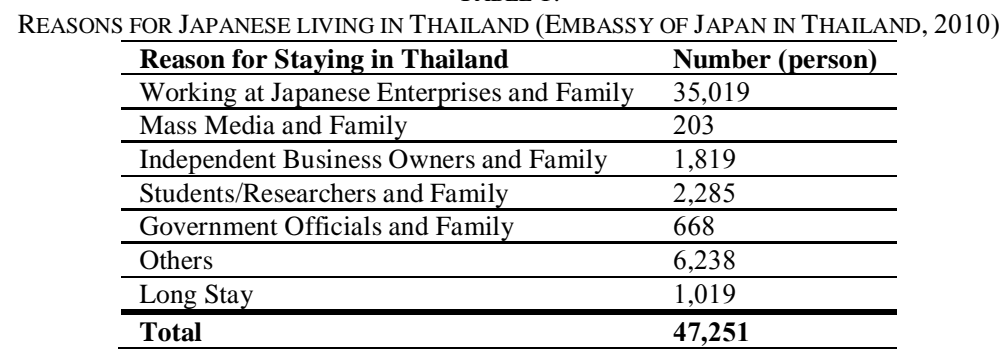

In addition, in the Annual Report of Statistics on Japanese Nationals Overseas, it has been noted that Thailand was ranked seventh in the world among countries that have a high number of Japanese national residents, and was ranked fourth in long-term settlement. Bangkok was ranked fourth among the capitals that are popular for Japanese to stay following Los Angeles Angels, New York and Shanghai (Japan Ministry of Foreign Affairs, 2009, p. 8).

Regards to Japanese business investment in Thailand, the data shows that Japan is the country that has highest investment in Thailand (Department of Business Development, 2009). Moreover, a survey conducted by the Japanese Chamber of Commerce in Thailand or JCC (2010) reports that, currently there are a total of 1,317 Japanese enterprises doing business in Thailand which can be classified as follows: manufacturing industry, the biggest sector in the country, occupies 51.4 percent; commerce and trade 16.6 percent; aviation and transport 5.4 percent; construction 5.3 percent; hotels and restaurants 4.1 percent; finance insurance and securities 3.6 percent; retail and department stores 2.1 percent; advertising and printing 1.8 percent; travel and hospitality 1.4 percent; governmental agency 0.7 percent; nongovernmental organizations 0.3 percent; and others 7.2 percent. Furthermore, the data shows that there were 1,164 companies registered in 2001, and 1,317 companies in 2010, which means that the registered rate of Japanese enterprises in Thailand over the last 10 years has increased annually (JCC, 2010). When comparing Japanese enterprises to other foreign enterprises invested in Thailand from March 2000 until May 2011, there were 2,714 foreign enterprises authorized to invest in business in Thailand while 978 enterprises, or 36 percent, were Japanese businesses (Department of Business Development, 2011). The JCC has grouped Japanese businesses and organizations which have become its members into 11 categories as follows: Manufacturing Industry occupies 51.4 percent of overall members, Commerce and Trade 16.6 percent, Aviation and Transportation 5.4 percent, Civil and Construction work 5.3 percent, Hotels and Restaurants 4.1 percent, Retail and Department Stores 2.1 percent, Finance/Insurance/ Securities 3.6 percent, Advertising and Printing 1.8 percent, Tourism and Services 1.4 percent, Government Agencies 0.7 percent, and NonGovernmental Organizations 0.3 percent (JCC, 2010, p. 8).

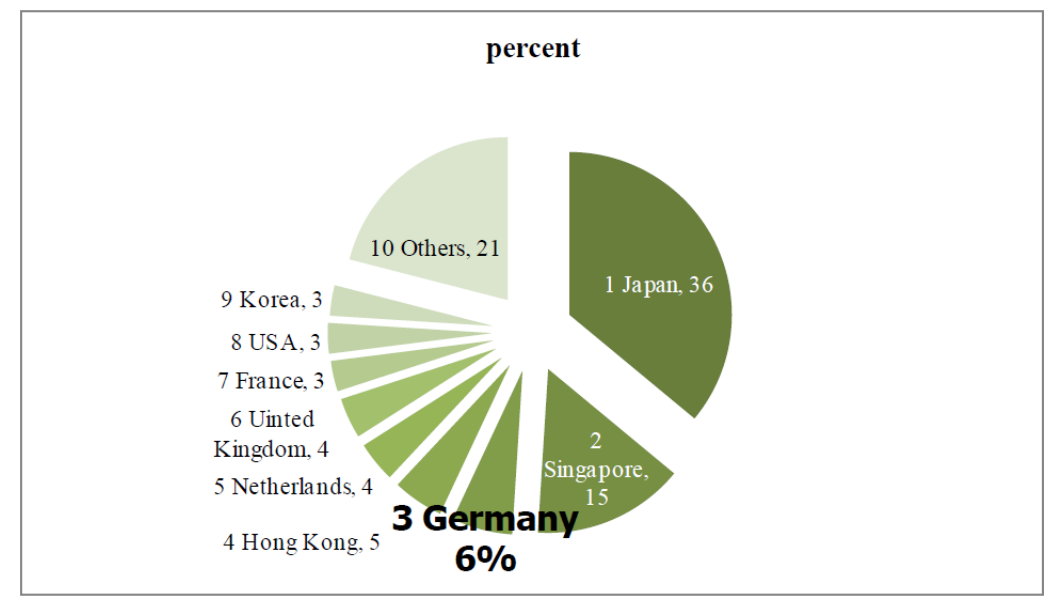

Figure 2: Foreign enterprises authorized to engage in business in Thailand from March 2001 until May 2010 separated by country (Department of Business Development, 2011).

\section{B. Development of Japan Studies in Thailand}

In Thailand, it has been recorded that Japanese language education was first introduced to Thailand in 1947 when Mattayom Wat Borpitpimuk School, which is now Rajamangala University of Technology Rattanakosin and Rajamangala University of Technology, started a basic Japanese course at secondary level. However, formal education in Japanese language began in 1965 when Thammasat University began a course, followed by Chulalongkorn 
University ${ }^{1}$ which started a similar course in 1966 and ran the first full-time undergraduate major course in Japanese in 1971. In 1981, Japanese was officially adopted at Thai secondary level as one of the second foreign languages of the National Curriculum. Since then, Japanese language courses at both secondary and tertiary levels have grown remarkably (Kakazu, 2010, p.16-17). Later, basic education curriculum, revised in 2001, enabled the establishment of Japanese language classes in lower secondary education, and accordingly, the number of Japanese teachers who graduated from universities in Bangkok dramatically increased, and Japanese language education gradually spread to other universities, even outside the capital. The statistics shows that Thailand is now placed the $7^{\text {th }}$ in the world and $2^{\text {nd }}$ in the Southeast Asian region after Indonesia in the number of Japanese learners, with nearly 720,000 (Kakazu, 2010 , p. 17).

Recently, according to a survey of Japan Cultural Center in Bangkok in 2008, there were 89 universities from a total 112 universities in Thailand that provide Japanese language education. Among these universities, 21 have Japanese language as a major subject for undergraduate program. Moreover, Chulalongkorn University (courses mostly focus on language and literature), Thammasat University (Japan studies) and Naresuan University (Japan studies) have graduate programs related to Japanese language studies (Japan Foundation, 2010), as well as National Institute of Development Administration, which is also opening its first graduate school in Japanese Communication and Culture providing Japan studies in 2012. Only Chulalongkorn University provides a doctoral program majoring in Japanese literature. On the other hand, universities that focus on development of human resources in Japanese language teaching are Khonkaen University, which opened its course within Faculty of Education in 2004, and Burapha University, which opened its course in 2005 (Japan Foundation, 2010).

TABLE 2:

CHRONOLOGICAL LIST OF JAPANESE LANGUAGE EDUCATION HISTORY IN THAILAND (JAPAN FOUNDATION, 2010).

\begin{tabular}{|c|c|}
\hline Date & Event \\
\hline 1947 & Mattayom Wat Borpitpimuk School started a basic Japanese course \\
\hline 1965 & Thammasat University started Japanese course (as major subject in 1982) \\
\hline 1966 & Chulalongkorn University started Japanese course (as major subject in 1971) \\
\hline 1976 & Kasetsart University started Japanese course (as major subject in 1983) \\
\hline 1977 & Chiangmai University started Japanese course (as major subject in 1987) \\
\hline 1980 & $\begin{array}{l}\text { Khon Kaen University, Faculty of Humanities and Social Sciences started Japanese course (as } \\
\text { major subject in 2004) } \\
\text { University of the Thai Chamber of Commerce started Japanese course (as major subject in 1986) }\end{array}$ \\
\hline 1981 & Japanese was officially adopted at Thai secondary level \\
\hline 1982 & Prince of Songkla University, Pattani Campus started Japanese course (as major subject in 1996) \\
\hline 1983 & Silpakorn University started Japanese course (as major subject in 1997) \\
\hline 1984 & $\begin{array}{l}\text { First Japanese Language Proficiency Test }{ }^{2} \\
\text { Burapha University started Japanese course (as major subject in 1996) }\end{array}$ \\
\hline 1986 & $\begin{array}{l}\text { Naresuan University started Japanese course (as major subject in 1995) } \\
\text { Center for Japanese Studies founded at Thammasat University }\end{array}$ \\
\hline 1987 & $\begin{array}{l}\text { King Mongkut's Institute of Technology Ladkrabang started Japanese course (as major subject in } \\
\text { 1997) }\end{array}$ \\
\hline 1988 & $\begin{array}{l}\text { Assumption University started Japanese course (as major subject in 1988) Association of Japanese } \\
\text { Language Education in Thailand }\end{array}$ \\
\hline 1989 & Rangsit University started Japanese course (as major subject in 1998) \\
\hline 1997 & Thammasat University started master program in Japan Studies \\
\hline 1998 & Japanese became one of subjects for college admissions \\
\hline 1999 & $\begin{array}{l}\text { Chulalongkorn University started master'a program in sJapanese literature and Japanese language } \\
\text { studiesr }\end{array}$ \\
\hline 2002 & Srinakharinwirot University, Faculty of Humanities started major in Japanese Language \\
\hline 2003 & Japanese Teachers Association in Thailand (JTAT) was founded \\
\hline 2004 & Khon Kaen University, Faculty of Education started Japanese Language Education program \\
\hline 2007 & $\begin{array}{l}\text { Chulalongkorn University started master program in 'Japanese as a Foreign Language' (Japanese } \\
\text { Language Teacher Training Program) }\end{array}$ \\
\hline 2009 & Naresuan University started master program in Japan Studies \\
\hline
\end{tabular}

Based on data from 2009, there are a total of 377 institutions that teach Japanese language, with 1,240 teachers and 78,802 students in Thailand. The number of those who take the Japanese Language Proficiency Test tends to increase by approximately 17,000 persons each year (Japan Foundation, 2010).

\footnotetext{
${ }^{1}$ Thammasat University and Chulalongkorn University are the two leading universities in Thailand.

${ }^{2}$ The Japanese-Language Proficiency Test (JLPT) has been offered by the Japan Foundation and Japan Educational Exchanges and Services since 1984 as a reliable means of evaluating and certifying the Japanese proficiency of non-native speakers. The JLPT has five levels: N1, N2, N3, N4 and N5. The easiest level is N5 and the most difficult level is N1. N4 and N5 measure the level of understanding of basic Japanese mainly learned in class. N1and N2 measure the level of understanding of Japanese used in a broad range of scenes in actual everyday life. N3 is a bridging level between N1/N2 and N4/N5. (JLPT, 2011)
} 
Referring to overall education about Japan in Thailand, Pasuk argued that despite a rapid increase in Japanese language education, teachers and students, there is still insufficient understanding of Japanese society and culture. As a consequence, forthcoming education related to Japan should be more focused not only on Japanese language, but also Japan history, economics, philosophy and culture (Pasuk, 2007). However, as mentioned above, most institutes providing courses about Japan tend to be putting more emphasis on Japanese language (Tuenjai, 1994). Although the importance of understanding social and cultural aspects cannot be ignored, most researches in education about Japan in Thailand usually focus on 'Japanese language' education (Teunjai, 1994; Napasin, 2006; Ikeda, 2006; Sakuma, 2006). Focusing on the needs of Japanese language use in business, Tuenjai (1994) found that Japanese language education in Thailand is still not practical enough to be applied in the professional arena and proposed that more postgraduate degrees in Japanese language should be established in order to provide the higher skill required. Ikeda's survey on the needs of Japanese speaking staff in Japanese business shows that most Japanese business in Thailand use English as a formal language to communicate more than Japanese but still require staff who has gained level 2 in the Japanese Language Proficiency Test and have good cognition in technical terms (Ikeda, 2006).

However, despite the long relationship between Japan and Thailand, the steady expansion in numbers of Japanese residents and business, and also the high demand of Japanese speaking human resources (Adecco-Asia, 2011), universities that provide undergraduate courses related to Japan is still limited and mostly focused on language education, with only four institutes having a master's program and just one university having a doctoral program. Among these, only three courses offer programs related to Japan studies which include in-depth socio-cultural aspects into the program.

\section{THE STUDY}

In spite of the fact that Japan has became highly recognized and Japanese language studies have been widely attractive to Thais, some data about those who have graduated in this field are very few, making it difficult to understand the whole situation concerning graduates (Japan Foundation, 2010). Aiming to understand more about the expectations towards human resources in Japanese language, including those from Japanese enterprises, as a baseline information to improve a better curriculum to produce qualified graduates for the labor market, this study tries to understand the expectations towards the quality of graduates in Japan and Japanese language studies as well as expectation towards courses related to Japan Studies by collecting data from two different target groups which are: (1) 123 questionnaires respondents and 25 key informants taken from among those who have graduated in Japan and Japanese Studies in Thailand and are currently working at Japanese-related firm; and (2) 52 questionnaires respondents and 14 key informants from among Japanese who work in Thailand and have experience working directly with Thai graduates. A questionnaire was distributed to the target group followed by an interview with several key informants. In all, 175 persons responded to the questionnaire and 39 persons provided information as key informants of this study.

\section{A. Quantitative Approach}

Related to a background of those who responded to the questionnaire, the study found that 85 percent are women, while only 15 percent are men. The reason why choosing Japanese language as their major subject is not much different, most said because they like Japan and Japanese pop culture or some dreamt about a high income after graduation. When separated by job category, more than half of respondents are interpreter/translator (working in Japanese firm or freelance), coordinator or Japanese language teacher. Among the respondents, 35 percent works as an interpreter in the manufacturing business. From the data above, it can be assumed that a career path for those who graduate in Japan or Japanese language studies has little variation.

The result of the study can be categorized in three points: (1) related to the employment of the graduates, (2) related to expectations toward the qualification of the graduates, and (3) related to satisfaction with the quality of the graduates.

Related to expectations toward qualifications of the graduates, the study found that almost all Japanese businesses in Thailand still have demand for Japanese speaking staff considering that these staff will support better communication in the organization. Some organizations already hire Japanese speaking personnel, while some have a demand but still cannot find any proper human resources (figure 3). Only 14 percent consider it is not necessary to hire Japanese speaking staff, giving reasons such as 'All Japanese in the organization can speak Thai', 'All clients are Thai' or 'Language used in the organization is English.' Concerning the needs between hiring Japanese speaking Thai staff and Thai speaking Japanese staff, 75 percent of respondent prefer Japanese speaking Thai staff. Most of the reason for this is because 'Thai staff take lower salary', 'comfortable to work with' and 'can understand Japanese organizational pattern.' When considering about type of a job required, Japanese-speaking staff are highly necessary in sales and marketing followed by administrator, coordinator, interpreter, technician and management. More than 75 percent of the respondents found it remarkably difficult to recruit qualified human resources who can speak and work with Japanese. Only two percent do not consider recruiting Japanese speaking a problem at all (figure 4). 


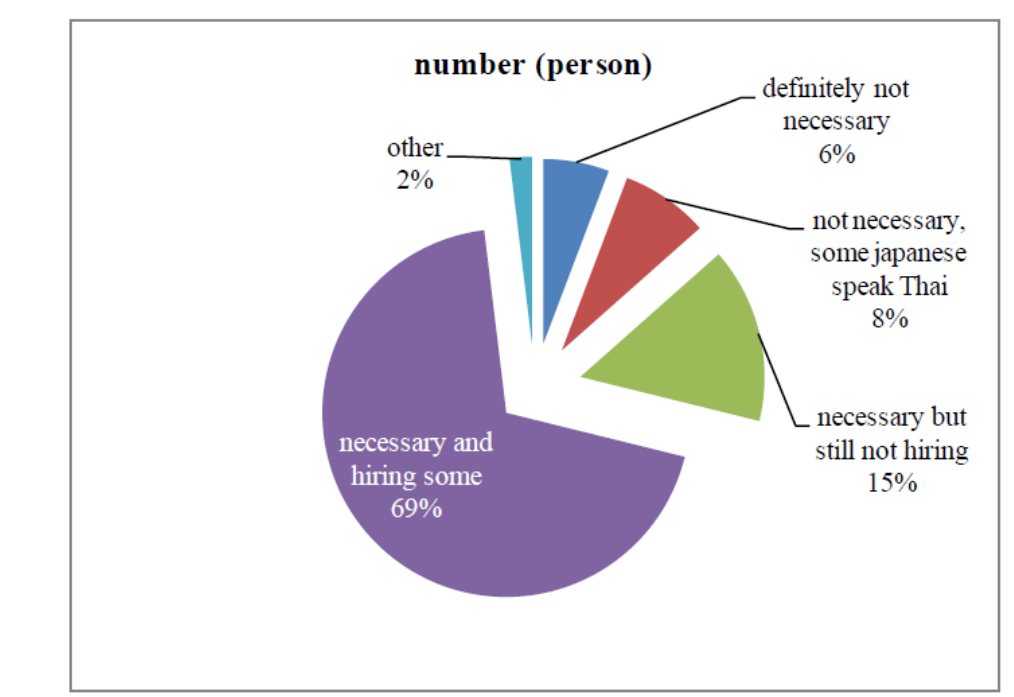

Figure 3: Need to hire Japanese speaking staff in Japanese related organizations in Thailand.

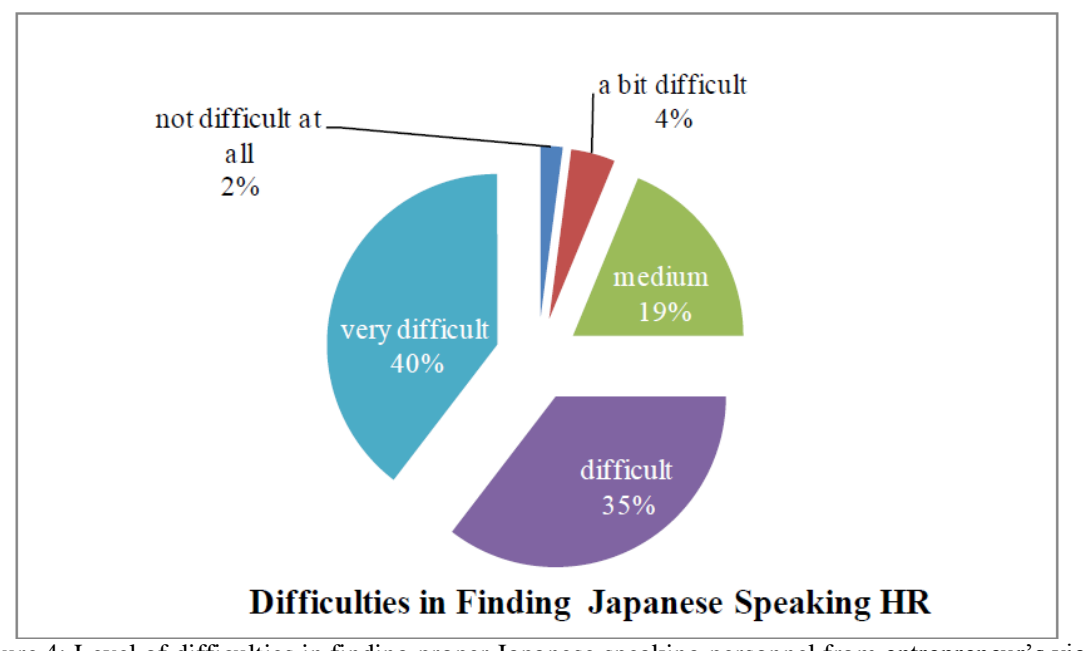

Figure 4: Level of difficulties in finding proper Japanese speaking personnel from entrepreneur's view

Similar to Ikeda's finding that most enterprises in Thailand use English as a formal language (Ikeda, 2006), this study also found that 50 percent of the enterprises who responded to the questionnaire use English as a formal language to communicate in their organization which means that main language popularly used in Japanese related organization is still English. On the other hand, organizations that use Japanese or Thai as a formal language and have a Japanese-Thai interpreter to translate the conversation are about 10 percent each (figure 5).

Among the graduates, the study found that because 40 percent of the respondents have Thai supervisors, 24 percent use Japanese occasionally in spite of working in a Japanese related firm. Those who use both Thai and Japanese in the same frequency are 23 percent. A total of 44 percent of the respondents use Japanese frequently at work while only the remaining 10 percent said they use Japanese very little or even do not use Japanese at all.

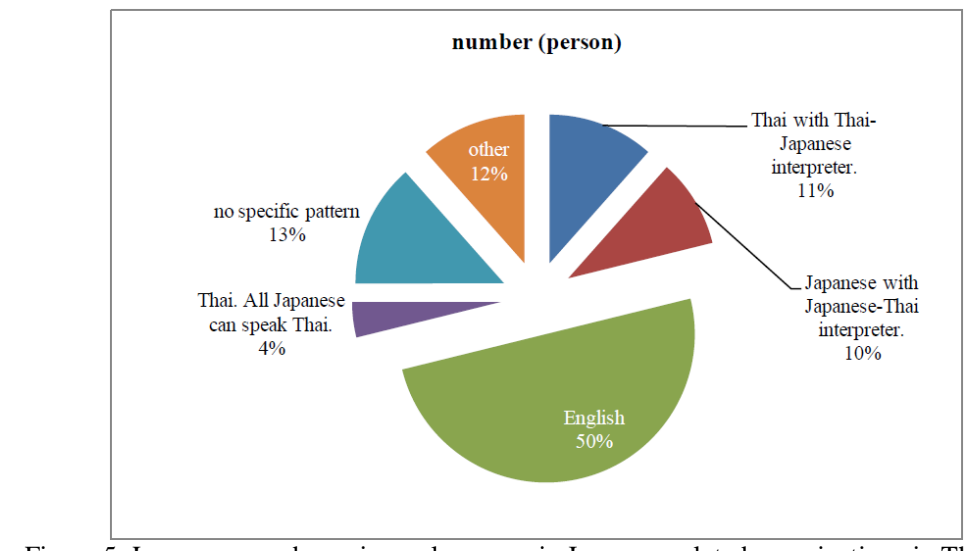

Figure 5: Language used as primary language in Japanese related organizations in Thailand. 


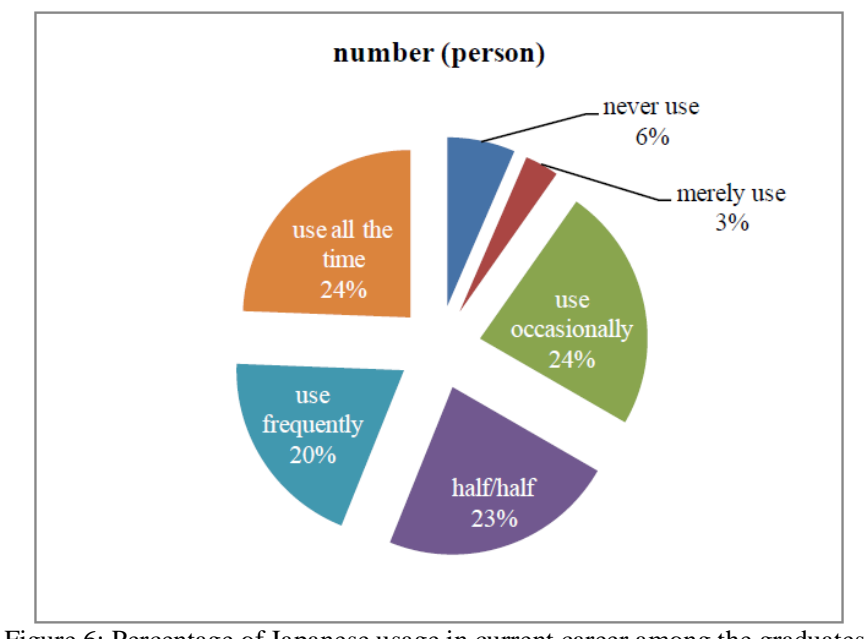

Figure 6: Percentage of Japanese usage in current career among the graduates.

From the results it can be concluded that the expectations of the Thai graduates and the expectations of the entrepreneurs are different, with the graduates having the highest expectation in a proficiency of Japanese language using especially speaking skill, reading skill and listening skill followed by interpreting/translating skill. The other skills such as 'writing skill', 'understanding of Japanese culture', 'coordinating skill', and 'management skill' received less interest from the respondents. On the other hand, the entrepreneurs have a different perspective. They consider an ability and capacity in working in all aspects the most important and also have the highest expectation in this factor. As a consequence, they require persons who can apply Japanese language ability to the task assigned, know how to deal with problems and produce the best result that can increase the company's profit. Most entrepreneurs need to hire those who have passed level N2 of Japanese Language Proficiency Test (67 percent), followed by 23 percent that require level N1 which is the highest level of the test. Only 10 percent are satisfied with level N3 or N4 (figure 6). When separated by working skill, the study found that the skill that the entrepreneurs expect the most is 'coordinating skill' and 'accuracy.' Similar to the Thai graduates, understanding of Japanese politics and economics received least expectation also from the Japanese entrepreneurs.

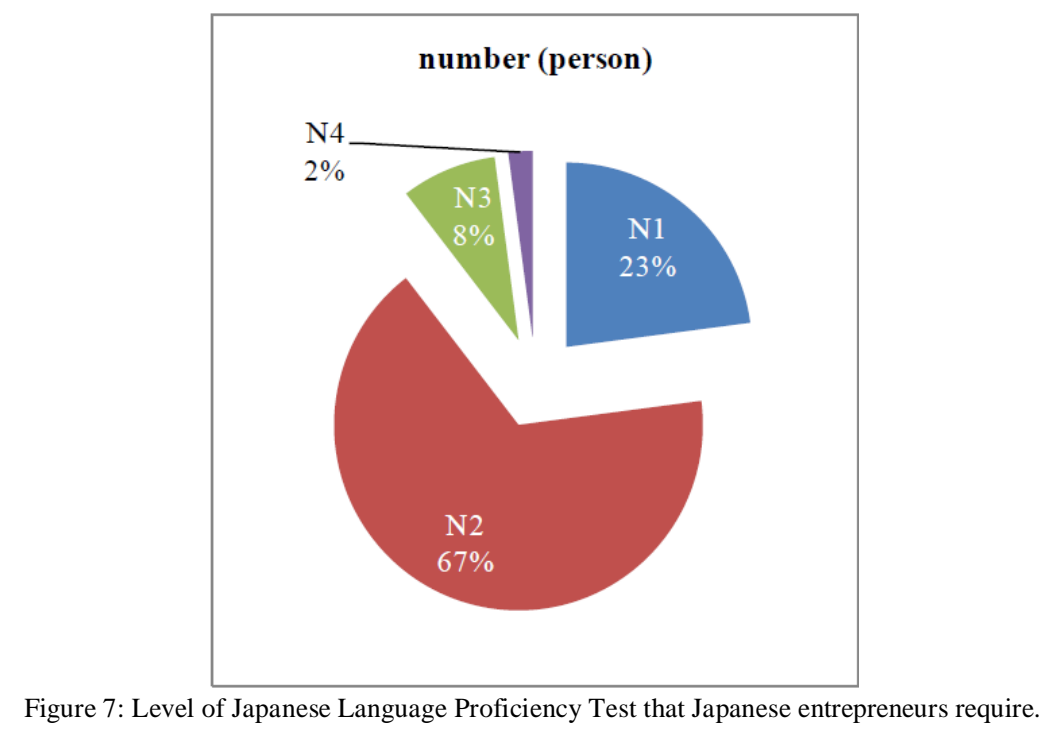

Related to satisfaction of the quality of the graduates, both the Thai graduates, who evaluated themselves, and the Japanese entrepreneurs, who evaluated the graduates, found that ability in all skills is at the medium level. Among these, both sides consider Japanese language usage, especially in everyday conversation, the skill with highest satisfaction.

\section{B. Qualitative Approach}

In order to gather more in-depth information about problems of Thai Japanese speaking human resources and Japanese entrepreneurs have to confront as well as the type of program expected, a key informant interview with both sides was conducted. In terms of problems and difficulties working with Japanese, most Thai graduates found Japanese kind, sincere and thinking about other more than one's self. However most people think that Japanese are comparatively too serious with everything especially when relating to work which makes it difficult for the Thais to cope with, and it 
is necessary to adjust oneself to get along with the Japanese and Japanese organizations. What the Thai graduates consider as difficulties working with Japanese can be separated into two factors:

1. ways of thinking and cultural perspective such as the way the Japanese concentrate seriously on work, strict system and output based structure, etc.

2. style of language usage and communication such as habit of fast-talking, different level of language usage which is difficult to use and understand, too many Chinese characters, do not express things in direct way, etc.

When focusing on factors they need to develop in order to work effectively with Japanese, most of the graduates consider basic language using (listening, reading, speaking and writing) skills as the first they need to improve while some think that working skills such as coordinating skills or problem solving skills are also important. As one key informant put it:

Listening and speaking skills are the most important when you have to work with Japanese. But Japanese language education in Thailand still cannot develop these two skills effectively, probably because it is still a 'memorization-only study' with not much focus on learning in a real situation. I think we need to learn to speak more both in everyday conversation and in business situation. It is also necessary to learn conversation that can be used in our future career.

On the other hand, what the Japanese entrepreneurs expect from the Thai graduates is much different than what the Thai graduates perceive. Basically, most Japanese entrepreneurs consider language ability a basic skill that graduates in this field need to have and not what they should expect as they believe the ability in Japanese language is obviously what all graduates in this field are supposed to have and it is not an element that should be considered as an 'expectation.' The expectation of Japanese entrepreneur towards Thai graduates required as company personnel is summarized in table 3 .

TABLE 3:

EXPECTATIONS JAPANESE ENTREPRENEURS HAVE TOWARD THAI GRADUATES IN THE FIELD OF JAPAN STUDIES.

\begin{tabular}{|c|c|c|}
\hline No. & Expectation & Details \\
\hline 1. & $\begin{array}{l}\text { Overall working ability together with language } \\
\text { skills }\end{array}$ & $\begin{array}{l}\text { Understand Japanese way of thought includes Japanese working style; } \\
\text { Use Japanese language as a 'tool' to improve working ability such as } \\
\text { coordinating and communicating with Japanese. }\end{array}$ \\
\hline 2. & Personality and morals & $\begin{array}{l}\text { Having common sense; Mentally strong; Do not hesitate to ask; Do } \\
\text { not focus too much only on salary. }\end{array}$ \\
\hline 3. & Specific skills & $\begin{array}{l}\text { Knowledge in different fields such as management, engineer, } \\
\text { accounting; Ability in English; Ability in Business Japanese; Ability } \\
\text { in translating Thai-Japanese. }\end{array}$ \\
\hline '4"' & Language skills only & $\begin{array}{l}\text { Few consider that only everyday Japanese conversation is enough for } \\
\text { working in Japanese business and other skills can be developed } \\
\text { together with work experience. }\end{array}$ \\
\hline 5. & No Japanese language skills required & $\begin{array}{l}\text { Few consider Japanese language not necessary at all for the company } \\
\text { since most clients are Thai and the common language in the company } \\
\text { is English. }\end{array}$ \\
\hline
\end{tabular}

Related to teaching style expected in university, especially in graduate school level, both Thai and Japanese respondents require methods that are more practical and useful. Most of respondents need on-the-job training to prepare themselves for working with a Japanese company after graduation. Teaching style proposed by respondents is summarized as:

1. Practice based lesson. Can be separated into two levels: in class activities such as role playing, workshop, case studies, experience sharing between present students and former graduates; and internship program which provides students the opportunity to work in Japanese firms (factories or hospital, hotel businesses) for a short period. Applying different tools and media in class, not limited only on books or reading materials.

2. Participation with Japanese. It is important that students have to become use to communicating with native Japanese. Not only Japanese teachers, but opportunity to discuss, sharing experience or even become friends with Japanese can improve language ability as well as understanding the Japanese way of thought and culture. This activity has to be done by Japanese, arranged as often as possible and continuously in various forms, for example cultural exchange program, training program in Japanese firms, orientation to working with Japanese. Encourage students to study in Japan has also been raised as one important factor.

3. Holistic program. One problem Thai graduates confront is knowledge and skill that is too narrow. Programs should be able to provide a wider range of skills development such as business management skills, computer skills or even distress tolerance skills.

4. Lessons and curriculum based on professional development. Since it is easier to find a better job, students should gain level N2 of Japanese Language Proficiency Test and became an intern in a Japanese firm as a prerequisite for graduation. Also the program should have courses that improve interpreter/translator skills in specific circumstances. If time is not available, short-term programs should be strongly considered.

\section{The AnAlysis: Perception GaP BetweEn the Thais AND the JaPANESE}


Regarding expectations and satisfaction toward the ability of Japanese speaking human resources, the results can be summarized as follows (table 4).

TABLE 4:

COMPARISON OF EXPECTATIONS AND SATISFACTION TOWARD THE ABILITY OF JAPANESE SPEAKING HUMAN RESOURCES

\begin{tabular}{|c|c|c|c|c|}
\hline & Thai Graduates & $\begin{array}{l}\text { Japanese } \\
\text { Entrepreneur }\end{array}$ & $\begin{array}{l}\text { Organizations with mostly } \\
\text { Thai Shareholders }\end{array}$ & $\begin{array}{l}\text { Organizations with } \\
\text { mostly Japanese } \\
\text { Shareholders }\end{array}$ \\
\hline Highest Expectation & $\begin{array}{l}\text { development in } \\
\text { language ability }\end{array}$ & $\begin{array}{l}\text { development in } \\
\text { overall working } \\
\text { skills }\end{array}$ & $\begin{array}{l}\text { skills in language and } \\
\text { communication }\end{array}$ & overall working skills \\
\hline Highest Satisfaction & language skill & $\begin{array}{l}\text { skill in everyday } \\
\text { conversation }\end{array}$ & & \\
\hline Total Expectation & high & high & & \\
\hline Total Satisfaction & medium & medium & & \\
\hline
\end{tabular}

From the above findings, it can be analyzed that there are apparently differences in perception among the Thai and the Japanese, that is the Thai, both the graduates and the entrepreneurs, expect and place a heavy emphasis on language using ability, while on the other hand, the Japanese consider language ability an essential skill of those who have gained a bachelor's degree related to Japan studies. Accordingly, what they expect is more focuse on the ability to work in a Japanese organization. These differences in perception indicate a weakness in the education system and results in a lack of qualified human resources for the labor market. As a consequence, graduates that have only language skills cannot fulfill the expectation of their employers. Further, the data collected also shows that despite a variation of Japanese business in Thailand, Thai graduates find job opportunities mainly as a translator/interpreter/coordinator in manufacturing business or as a Japanese teacher. All of these factors result in an unsatisfactory outcome in the production of Japanese speaking human resources that does not suit what is required in the real labor market. Also, this is a reason why employers find it is comparatively difficult to hire qualified Japanese speaking personnel for their business.

From the above findings, the following can be concluded:

- There is a gap between the level of expectation and satisfaction both of the Thai graduates and the Japanese entrepreneurs. This fact implies that despite a high expectation from important stakeholders, the quality of graduates is still not high enough and the graduates still cannot provide adequate service to society. Several reasons can be detected, but it cannot be ignored that the role of universities in teaching about Japan and Japanese should be reconsidered.

- There is still not enough Japanese-speaking graduates that also have in-depth understanding about Japan sociocultural aspects and can satisfy Japanese entrepreneurs. Accordingly, universities and related institutes should reconsider and improve their educational program in order to produce graduates that really have qualifications that suit the real professional arena by spending more time on different skills that can lead to the improvement of capacity in working with Japanese.

- Most education in Thailand are focusing only on Japanese language while Japanese firms require human resources that are qualified not only in language proficiency but also in working performance, resulting in a shortage of properly qualified human resources.

- Most students related to Japan education consider interpreter, translator or Japanese language teacher as the jobs they can find after graduation, while the demand for Japanese speaking human resources is not limited to a specific field such as interpreter or translator, but has some variation, especially for sales persons.

\section{DisCUSSION AND CONCLUSION}

The fact that most Japanese entrepreneurs in Thailand still face a problem in finding proper Japanese speaking personnel in spite of the increasing number of Japanese language learners, and also that many graduates who work in Japanese related organizations find some difficulties in working with Japanese, especially in the cultural aspect, implies that the quality of human resources in this field is still not at a satisfied level. One reason found in this study is because Japanese related education in Thailand is still focusing on language ability improvement through passive lessons focused on rote memory rather than by experiencing more real situations or providing students with more skills that can be applied in their careers. As a consequence, in order to reach the level expected, improvement in the quality of both the learner and educator is needed.

Several suggestions are proposed here. First, since there is a perception gap about the ability of Japanese speaking human resources, it is necessary to make a right understanding about what is expected by Japanese employers to both learners and educators. Either Learners or educators should recognize that focusing on improvement of language ability is important but not the only skill needed to develop because it is not enough to satisfy the expectation of Japanese employers in professional arena. Other skills such as managing skills, problem solving skills, coordinating skills, interpersonal skills, distress tolerance skills, or even English skill, are not less important if one want to be satisfied and become success in career. Universities and institutes that offer courses related to Japan studies also have to concern about this fact and provide the most practical curriculum to learners, either to improve language ability or to improve 
working ability as a whole. It is also important to provide enough information about job opportunity that those graduates in this field can have, to let them know that there are varieties of businesses waiting for them to apply for, not only just manufacturing business or teaching business as they may assume.

Another important factor needing improvement is the number of Japanese speaking human resources. It can be concluded from the findings that personnel in this field are required not only to be proficient in language use but also have an understanding of Japan and Japanese culture. One of the reasons for this would be because of the education that focuses more in the development of language ability than the development of understanding of Japanese culture or working in real situation outside the university. Accordingly, more universities should offer courses in Japan Studies, which focuses also on Japanese culture and society as well as the way of thought and beliefs, and should emphasize real practice, and include the opportunity to communicate with native Japanese speakers in different situations, promote skills that can be applied after graduation.

\section{REFERENCES}

[1] Adecco-Asia (no date). Adecco's survey of recruiting in Thailand 2011. http://www.ejobeasy.com/kmdetail.php?n=101224174909 (accessed 29/12/2011).

[2] Department of Business Development (2009). Department Service. Ministry of Commerce. http://www.dbd.go.th/mainsite/index.php?id=22647 (accessed 24/11/2009).

[3] Department of Business Development (no date). The authorization of business certification in 2011. Ministry of Commerce. http://www.dbd.go.th/mainsite/index.php?id=22647 (accessed 24/11/2011).

[4] Embassy of Japan in Thailand (2010). Acknowledge about Living in Thailand. http://www.th.embjapan.go.jp/jp/consular/zairyuto.htm\#調査 (accessed 10/11/2011).

[5] Ikeda, T. (2006). The survey of Japanese language needed in Japanese companies (manufacturing business). Japan Foundation. Bangkok Cultural Center. Journal of Japanese Language Education 3, 227-232.

[6] Immigration Bureau (2010). Number of Tourists Visited Thailand. Police Department. http://www2.tat.or.th/stat/web/static_index.php (accessed 15/11/2011).

[7] Japan Foundation (2008). Tawan. Japanese Language Department. The Japan Foundation: Bangkok.

[8] Japan Foundation (2010). Results of the 2010 survey of overseas Japanese language educational institutions: Thailand. http://www.jpf.go.jp/j/japanese/survey/country/2010/thailand.html\#JISSHI (accessed 15/12/2011).

[9] Japanese Chamber of Commerce (2010). List of Members. Japanese Chamber of Commerce: Bangkok.

[10] JCC Bangkok (2010). JCC. Japanese Chamber of Commerce: Bangkok.

[11] JLPT (no date). Japanese-Language Proficiency Test. http://www.jlpt.jp/e/about/message.html (accessed 22/12/2011).

[12] Kakazu, K. (2010). Retrospective and Prospects of the Japan Foundation Through its Activities in Thailand. Japanese Studies Journal 27.1, 13-19.

[13] Ministry of Foreign Affairs (2009). Annual Report of Statistics on Japanese Nationals Overseas. Japan. www.mofa.go.jp/mofaj/toko/tokei/hojin/10/pdfs/1.pdf (accessed 28/11/2011).

[14] Ministry of Foreign Affairs (2011). Japan-Thailand Relations. http://www.mofa.go.jp/region/asia-paci/thailand/ (accessed 28/11/2011).

[15] Napasin P. (2006). Ways to teach Thai students Japanese. Japan Foundation. Bangkok Cultural Center. Journal of Japanese Language Education 3, 227-232.

[16] Pasuk, P. (no date) The State of Japanese Studies on Social Science in Thailand. Institute of Social Science. University of Tokyo. http://pioneer.netserv.chula.ac.th/ ppasuk/japanesestudiesinthailand.pdf (accessed 24/11/2011).

[17] Sakuma, K. (2006). Rethinking about Teaching Japanese as a Second Language. Japan Foundation. Bangkok Cultural Center. Journal of Japanese Language Education 3, 17-28.

[18] Teunjai, T. (1994). The survey of Japanese language use and requirements of the private sector. Research Institute. National Institute of Development Administration: Bangkok.

Nareenoot Damrongchai is a lecturer at Graduate School of Language and Communication, National Institute of Development Administration, Thailand. She received her Ph.D. in History and Area Studies at Hokkaido University, Japan. She has special intere st in Japan studies, development communication and crisis communication. 